\title{
On the Alternative Approach to Artifacts in Environmental Education
}

\author{
Magdalena Holy-Luczaj \\ University of Information Technology and Management in Rzeszow, POLAND* \\ Kamil Luczaj \\ University of Information Technology and Management in Rzeszow, POLAND
}

\begin{abstract}
This paper advocates developing an alternative path for encouraging environmentally responsible actions related to technical artifacts (useful, human-made objects). Environmental education can enhance the positive intrinsic motivation to care for and respect artifacts as unique individuals embedded in the network of functionality and not only because neglecting them may lead to an ecological catastrophe (negative intrinsic motivation) or because of external motivators, e.g. saving money (extrinsic motivation). Such a reinforcement of positive engagement with artifacts through environmental education may complement existing incentive strategies to behave in a pro-environmental manner. The paper concludes with suggestions for classroom activities targeted at undergraduate students for cultivating a revised understanding of everyday artifacts.
\end{abstract}

Keywords: artifacts; positive intrinsic motivation, environmental ethics, classroom activities

\section{Introduction}

Technical artifacts - as human-made objects serving functions (other than aesthetical) for human beings (Kroes, Vermaas 2008; Houkes, Vermaas 2004) - accompany us everywhere on a daily basis. Everyday artifacts obviously form a very diverse set of things. The following consideration focuses on physical artifacts (as different from digital ones), because they cause specific environmental problems related to the exploitation of natural resources and polluting the environment ${ }^{\dagger}$. Thus in the theoretical, activist, and media discourse on the ecological crisis artifacts are now perceived as the culprits. Their destructive impact on the planet is indeed incontestable. Having said that, we argue that presenting a negative image of artifacts as things that primarily harm nature can be an obstacle for pro-environmental thinking and behavior. Instead, we can seek to cultivate the alternative attitude towards artifacts, which would be grounded in the positive motivation to care for an artifact as something worthy of respect itself, not merely because its deterioration would be detrimental for the environment. Importantly, those two motivations do not need to compete - one need not be promoted over the other (Howell, Allen 2016: 13, 14). On the contrary, they can mutually strengthen each other.

\footnotetext{
* This research was supported by the grant Dialog (no. 0023/DLG/2019/10) from Ministry of Science and Higher Education, Republic of Poland.

$\dagger$ On the dissimilarities between physical and digital artifacts see Holy-Luczaj 2019. The latter also pose environmental threats which are likely go unnoticed at first glance. For instance, streaming, cloud storages, etc. contribute to our carbon footprint. A study focused on movie distribution revealed that "non-energy optimized streaming of a movie through the Internet consumes approximately $78 \%$ of the energy needed to ship a movie, but has a carbon footprint that is approximately $100 \%$ higher" (Seetharam et. al 2010: 61). Projections for the future show that data centres, along with production of ICT, consumer devices and networks, will account for more than 20 percent of projected global electricity demand (Jones 2020).
} 
Environmental education has a very important role to play in this regard, as it trains critical thinking and offers a variety of perspectives to enhance environmental awareness (Morrison 2018; Howell, Allen 2016; Breunig et al. 2014; Heimlich, Ardoin 2008). In this paper, we sketch such an alternative ethics of artifacts and offer some suggestions for classroom activities based on it.

The paper is organized into four sections. First, we discuss the significance of intrinsic and positive motivations for pro-environmental behavior, illustrating them with campaigns which may serve as resources for teachers. Next, we critically reconstruct the image of artifacts in environmental philosophy and its ethical implications. In the third part, we outline the alternative for it: a positive, pro-ecological ethics of artifacts. The fourth part presents classroom activities which can encourage students to look at artifacts differently.

\section{Typology of pro-environmental motivations}

Environmental education, being significantly different from straight environmental information, is a process that allows individuals to explore environmental issues, build and strengthen awareness for environmental problems, engage in solving them, and take action to improve the environment (EPA 2020). The landscape of environmental education is, however, diverse and dynamic, which leads to clashes between the various approaches. Within the field of environmental education, we can also see very clearly the debates about the purpose of education in general (Heimlich, Ardoin 2008: 215). Some argue that the ultimate purpose of education is to affect individuals' behavior and that conservation education, among other areas, aims specifically for behavioral change (Braun, Cottrell, Dierkes 2017; Ernst, Theimer 2011; Heimlich, Ardoin 2008). Others contend that the primary role of education is to facilitate an individual's intellectual capability and not to impose ideas on individuals regarding how they should live (Heimlich, Ardoin 2008). Furthermore, some scholars emphasize the effectiveness of private sphere environmentalism (Braun, Cottrell, Dierkes 2017; Aguirre-Bielschowskya, Freemana, Vass 2012: 91), while others find the promotion of environmental citizenship and the preparation of students for public action to be of more relevance (Hadjichambis and Pedro Reis 2019: 5). There are, however, hybrid models, which, on the one hand, aim to prepare students to become agents of change in the private and public spheres, on a local, national and global scale, through merging individual and collective actions (Jørgensen, Madsen, Læssøe, 2017; Parra et al. 2019: 151); and on the other, attempt to induce a behavioral change by raising pro-environmental awareness (Jørgensen, Madsen, Læssøe, 2017; Braun, Cottrell, Dierkes 2017). Our proposal adapts the perspective advocated by Braun, Cottrell, Dierkes (2017), who claimed that "changing behavior in this sense is more than changing specific actions. It means replacing old routines. This process requires much more willingness to change something because it is more than adding a new element. Instead it requires an entire rethinking of the everyday life" (Braun, Cottrell, Dierkes 2017; see Heimlich, Ardoin 2008: 219). In our considerations here, we attempt to rethink critically the way we perceive artifacts, precisely in order to boost the motivation to use them responsibly in environmental terms.

Motivating people to participate in pro-environmental activities is still believed to be a key mandate of environmental education (Dutta, Chandrasekharan, 2018; Cooke Fielding, Louis 2016). The motivation is similar to what Hungerford and Volk (1990) defined as 'intention to act', which Kollmuss and Agyeman (2002) further defined as commitment and willingness to take action (Mintz, Tal 2018). We discuss how environmental educators can develop the motivations of their students in the section 4. In what follows, we present the typology of pro-environmental motivations. 
The first distinction that we need to introduce is that of the extrinsic and intrinsic motivations. Such a classification, including also amotivation (lack of motivation), was proposed by Richard Ryan and Edward Deci in 1985 and is still being developed (Ryan and Deci 2020) and fruitfully employed in contemporary research (Cooke, Fielding, Louis 2016; Skinner et al. 2012; Darner 2012; 2009). According to it, extrinsically motivated behaviors are those regulated by forces outside the individual. For instance, one person may intend to recycle a plastic bottle to get a cash refund.

Intrinsically motivated behaviors regulated by the curiosity and inherent satisfaction arising from an individual's tendency to elaborate his or her organizational cognitive structure. A person driven by this motivation will recycle a plastic bottle because of his or her concern about the consumption of fossil fuels in the production of plastics (Darner 2009). As Mihály Csíkszentmihályi (2014: 174) puts it "such motivation reflects an experience that is an end in itself, a dynamic psychological state that is valued for its immediate rewarding qualities."

The extrinsic motivation is well-spread in pro-ecological communication by the NGOs, governmental organizations, as well as ecologically aware companies. A good exemplification is the 2012 American Rivers advertisement with a caption "Green to earn green. Greening a roof helps prevent river pollution but it can also save money" $\ddagger$. It is oriented toward measurable, external rewards for implementing a pro-environmental solution in our immediate surrounding.

An example of intrinsic motivation, in turn, could be the campaign of Segmento Company, which encourages people to act ecologically for the sake of nature. It appeals to human unity with nature (the slogan is: "Human and Nature are One") and illustrates it with the image of a tree in which the trunk and branches are a human hand\$.

This campaign appeals to affirmative emotionality: it highlights our sense of connectedness with nature and its beauty. The latter aspect leads us to another distinction: between negative and positive motivation, which applies to both intrinsic and extrinsic motivations (see: Table 1). Basically, positive motivation occurs when one wants to get something and negative motivation is when one wants to avoid something. Further, the first is related with positive feelings (happiness, pleasure, etc.), and the latter with negative ones (guilt, fear, etc.) (Donovan, Haley 2010: 139-141).

Table 1.

Exemplary extrinsic/intrinsic motivations and negative/positive argumentations strategies

\begin{tabular}{|l|l|l|}
\hline Motivations & \multicolumn{1}{|c|}{ Extrinsic } & \multicolumn{1}{|c|}{ Intrinsic } \\
\hline Negative & $\begin{array}{l}\text { Penalties for not sorting } \\
\text { garbage }\end{array}$ & $\begin{array}{l}\text { Feeling guilt for not } \\
\text { ceasing environmentally } \\
\text { destructive actions }\end{array}$ \\
\hline Positive & $\begin{array}{l}\text { Cash refund for recycling } \\
\text { plastic bottles }\end{array}$ & $\begin{array}{l}\text { Appreciating nature's } \\
\text { beauty }\end{array}$ \\
\hline
\end{tabular}

¥ The image is available at: https://www.adsoftheworld.com/media/digital/american_rivers_get_more_green [28.11.2020].

$\S$ The image is available at:

https://www.adsoftheworld.com/media/print/segmento_humanity_and_nature_are_one [28.11.2020] 
Regrettably, the pro-environmental discourse on artifacts is dominated by a negative intrinsic strategy. It can be illustrated with research on recycling and reducing clothing production and purchases. When scholars investigate motivations for recycling various reusable objects, it is assumed that these are either extrinsic motivation (e.g., to save money, to get a cash refund), or negative intrinsic motivation aimed at protecting nature by limiting consumption of fossil fuels required for the production of artifacts, diminishing waste, etc. (Jakovcevic et al. 2014; Simmons, Widmar 1990; see Johannson 2016). However, from the perspective of the artifact, the latter are neither intrinsic nor positive motivations: they are not oriented toward the artifact itself, but to nature (natural beings), and, furthermore, they are related to negative practices (limiting, diminishing, and by doing so not harming etc.). A similar tendency can be observed in the narrative on the reduction of the consumption of personal clothing, which is supposed to lower the harmful impact of the production of clothes on the environment (Joanes, Gwozdz, Klöckner 2020).

Let us take another look at the WWF campaign. The urban setting, insofar as it is obviously not a natural environment for penguins, is absolutely depressing in this context. The dark and dingy setting in the 'ad' is constituted solely of artifacts that are portrayed in such a way that it fills us with fear or despair and can trigger an even more critical attitude towards everyday objects. And while such an image can motivate us to undertake pro-environmental actions such as reducing driving, it does not necessarily help us to be devoted and mindful about objects in our immediate surrounding, which could in turn also have a pro-ecological impact.

To conclude, while it is self-explanatory that human activity related to production, use of artifacts and later waste management can be harmful and the effort should be taken to at least mitigate their effects, we argue that it would be beneficial to work out an alternative strategy to drive positive actions. Extrinsic motivation, oriented at external factors, is weak (Abrahamse, 2020: 145; Darner 2012; 2009). For instance, past generations tend to care more for things. But things used to be more expensive. Today, since toys, clothes etc. have gotten cheaper (Thompson 2014), we have become much more flippant in our dealings with them and replace them easily. On the other hand, motivation oriented solely toward nature (which is usually identified with intrinsic motivation, Darner 2012, 2009, Skinner et al 2011) and hostile towards artifacts in the long run may become tedious and repulsive. Some of us may feel tired of the permanent "put it down" narrative for the sake of the intangible "the environment" or "nature." It is necessary to understand that, related to behaviors, individuals are not all alike; they are not motivated by the same things, nor are they all equally capable of altering routines (Heimlich, Ardoin 2008: 231). There is a good chance that a new positive intrinsic motivation, encouraging being more attached to artifacts we already possess, will trigger in their case more desirable actions. For instance, they can encourage some people to use cloth bags (instead of disposable plastic bags) not out of an intention to diminish waste, but because they have their own bag, which they like, are attached to, and responsible for. Such a strategy does not aim to supersede or oust efforts targeted at restraining destructive activities performed by human beings, but rather complement them by introducing the wider array of possible strategies to raise ecological awareness.

In the following sections of the paper, we develop this idea in more detail, and support it with the example of an advertising campaign that fits this narrative. But before that it would be instructive to reconstruct the image of artifacts in environmental ethics to elucidate how deeply rooted the negative stance toward them is.

\section{Roots of environmental thinking about artifacts}

Environmental education and environmental ethics are inherently connected, because the former takes its premise from the latter (Moreira, Alves, Mendonça, 2020; Gola 
2017). Environmental ethics creates a conceptual framework for environmental education, laying out fundamentals for rethinking the way we live, understand ourselves and how we relate with our environment. It is essential to unpack the perception of artifacts in environmental ethics: it explains why environmental education has neglected to cultivate positive motivation towards them.

Artifacts, as we will see further, are basically understood as non-natural objects. This does, however, beg the question: what is nature? Environmental philosophy, which is not a single homogenous movement, does not offer one straightforward answer to this question. If we were, however, to indicate a common point on which the vast majority of paradigms could agree, it would probably be the sense of being independent from human beings (while the latter are dependent from nature as subjected to biological laws). This stems from the Aristotelian approach to the issue of the nature/artifacts divide. According to Aristotle, artifacts (which he defined as "created things") are not fully-fledged beings because, in contrast to natural beings ("growing things"), they do not have the principle of origin of the movement in themselves, but in the human beings who create them (Aristotle 1999).

Environmental ethicists who continue this line of reasoning point out to a twofold ontological, human-related dependence of artifacts. This concept assumes that artifacts are, on the one hand, anthropogenic - i.e. deliberately brought into existence by human beings (Siipi, 2003: 415-418). But unlike children, who may also be perceived this way, artifacts do not strive to sustain their own functional integrity (Callicott 2005: 189; Lee, 1999: 170-172). Furthermore, artifacts lack the ability to self-repair, self-maintain, and have no metabolism. In this manner, artifacts are similar to abiotic nature (Lee, 1999: 172 ), except that artifacts are secondary to the material from which they were made. For example, a tree is not derivative of wood, unlike a wooden chair (see Lee, 1999: 49-52; Holy-Luczaj 2019; 2020).

The second aspect of artifacts' dependence is their anthropocentric character - in the sense that their telos is humanly imposed and oriented toward human needs (Lee 1999, 73, see Katz 2018, 1993). In contrast, natural beings (animate and inanimate) are not placed within the frame of such intentional structures. They do not have the defined array of functions and do not exhibit such human purposiveness and end-directedness (see Lee 1999: 37-39; Holy-Luczaj 2019; 2020).

Being independent from human beings constitutes the core of the concept of "intrinsic value", which - for several reasons - needs further investigation. First, this is one of the key concepts discussed in environmental ethics. Second, it often serves as one of the clearest distinguishers of natural beings and artifacts. Third, we should avoid conceptual confusion by connecting the issues of "intrinsic value" and "intrinsic motivation."

Let us start with the latter. "Intrinsic motivation" and "intrinsic value," even though they are well-known notions in, respectively, environmental ethics and environmental education, are independent from each other. That is to say, despite both drawing upon the semantics of the adjective "intrinsic," they employ it in significantly different ways. Even though both refer to some sense of being inherent, they point to different spheres. The intrinsic motivation is about psychological factors related to undertaking certain actions (as discussed earlier), and intrinsic value - referred to sometimes as "inherent worth" - is the idea that a thing has a value of its own, irrespective of its contribution to some global or individual good. Thus these two cannot be automatically linked (or not, at least, without a solid argument, which would go beyond the scope of this paper).

As a matter of fact, while our proposal builds upon the idea of intrinsic motivation, it is quite critical of the idea of intrinsic value since it is defined primarily as a noninstrumental value (e.g. in Tom Regan or Arne Naess), which means that the goal of its existence is independent from any function it could serve other beings (particularly 
human beings). By contrast, when an entity has instrumental value, it serves some goal of another being (O'Neill 2002; see Naess 1984; Katz 2012; Holy-Luczaj 2019; 2020). What is of crucial importance is that for our considerations, natural beings are often seen to be of intrinsic value and artifacts of instrumental value (Brennan 1984, Katz 2018).

The conceptualization of intrinsic value as a non-instrumental is supposed to shake off the yoke of subordination, because using is usually seen as being dominated by some other being (usually human). This intention is clear and understandable. However, it unfortunately actually undermines environmental philosophy's attempt to convince people to recognize the interdependence of the different parts of the natural world. In broader terms, it suggests a peculiarly atomistic picture of the world. Nature is characterized by a mutual interconnectivity between everything, with each species serving specific functions for other organisms or entities. We do not need to perceive it in the vertical perspective ("lower" beings as servants of "higher" beings), but as a horizontal network of functionality (e.g. animals are not superior to trees but rather depend on them) (Weston 2006, 311; Holy-Luczaj 2019; 2020). This builds upon a pragmatist approach, which underlines that entities perceived from an environmental perspective exist primarily for each other and not merely for themselves. It highlights that we can respect and appreciate entities primarily for what they offer to and how they act in relation to other beings. Such a value of entities lies beyond the value they have for human interests and are not necessarily contaminated by power relations (see Hargrove 2012, pp. 178, 179; Holy-Luczaj 2019; 2020)). Such an approach, in which functionality is no longer entangled in the domination-subordination dependency, will play a major role in revising the status of artifacts, rendering them in our eyes valuable beings, functional in their own right; in addition, it will lay the foundations for a new, proecological ethics of artifacts.

\section{"The new positive motivation" - an alternative Image and Ethics of Artifacts}

Its first claim is that physical artifacts are individuals and as such are unique. This is in line with the ontological claim (with its roots in Aristotle) that any physical individual is single and does not have duplicates; materiality individualizes, making particular, unique things. In this sense there are no "copies" of the things - rather, everything is itself and not another, despite our inability to discern them sometimes. The unique status of each thing entails that each thing is unique even though we may find (or buy) an identical one - it will merely look identical, not truly be identical. That is to say, in a pile of the same color and the same size T-shirts, each of them is single and unique in the same way that every blade in a patch of grass is unique. This uniqueness applies to the most mundane and trivial objects, as the uniqueness in question is not a synonym for unlikeness, being special, exclusive, or unusual. This uniqueness is a great value which deserves human respect.

Mass production made us think that things are replaceable and replicable, but this belief that we can substitute one thing for another is, however, an (ontological) illusion. For instance, when we buy a new IKEA table because the old one was scratched and had few spots, we deal with another being, even though it looks exactly the same. We are always dealing with a distinct, "original" entity. We cannot "replace" one artifact with another. This argument is in line with Eric Katz's (2018; 2012) claim on the irreversibility of damaging or annihilating particular entities in the course of ecological restoration (we always plant another tree rather than recreating the old one). The only difference is that we do not limit this principle to natural beings; it also holds for physical artifacts, as in the case of the IKEA table. It is crucial to highlight their individuality because it is often ignored. The fact that artifacts are mass-produced does not change the fact that each of them is an individual entity. The foundation of this singularity is the materiality of artifacts, i.e. being built of tangible, palpable, corporeal material. A physical artifact, unlike a digital 
one, is materially tied/bonded to its particular, material source and cannot be separated from it. This renders it a unique thing.

Our appreciation of things can be further deepened by looking at their functionality. Functionality, as discussed earlier, does not make something subservient but instead can be thought of in terms of interrelatedness and interdependence, which constitute the community. It is worth elucidating some semantic differences between the terms "instrumental" and "functional." While they are basically synonyms, they have quite different rhetoric connotations: "instrumental" is a rather pejorative epithet that reduces a thing to a means to something else's goals. "Functional," on the other hand, is neutral or even positive. This adjective indicates the quality of being "practical," "useful," or "capable of operating and functioning", as well as "capable of serving the purpose for which it was designed" (Thesaurus 2019; Holy-Luczaj, Blok 2019.). Artifacts, which are functional objects per se, can also be seen in this manner. We do not have to perceive and treat them as "mere things," which are "only" to serve, but as entangled in the countless activities which wouldn't be feasible or much more difficult if there were no artifacts. This reversal of the perspective reveals that thanks to artifacts, we are able to perform certain activities instead of taking for granted that they accompany us in this. In other words, we should be aware of how necessary and helpful artifacts are - and how much we rely on them.

This is not, however, a one-way relationship: things also rely to a great extent on us. They are our things. We can refer here to the sense of "great possessions", which Aldo Leopold made one of the pillars of his environmental ethic. It is not tied with domination and control, but rather with responsibility and commitment. As Lisa Gerber (2018) showed in her brilliant essay, it is not merely about claiming another as our property possession can also entail being claimed by another (Gerber 2018: 269-270). If we were to extend to artifacts the set of things which deserve such a relationship, we could start seeing them as things that are related with us and for which we hold responsibility to maintain, keep in good condition, and simply, to care for.

Possession, as conceived by Leopold, embraces not only the sense of responsibility, but also of attachment. The latter is a relevant factor which can motivate environmental protection. There is considerable scholarly interest particularly in the relationship between place attachment and environmental behaviors (Junot, Paquet, Fenouillet 2018; Gosling; Williams 2010). Place attachment is a positive connection, or an emotional bond (the sense of connectedness) between a person and a particular place. We argue that such a relation can also be developed towards artifacts. Its manifestations can be found in advertising that promotes durable, high quality products. For instance, the 2017 Skoda advertisement convinces us, "This winter take really good care of your car". The visual is a knitted sweater in the form of the grill of a cartt. It tells us that insofar as people wear warm clothes to protect themselves from the winter cold, cars also need extra protective care in the winter.

This advertising evokes a sense of concern, care, even tenderness. In doing so, this visual shows that we can seek to cultivate such a bond between us and things we possess. And this bond is not something that chains us (as minimalism could calim)but rather involves in the wider context of things. When we look around, it becomes so evident that we are surrounded with things that are silent companions of our everyday life.

Despite the continuing debates regarding precisely how attitude links with environmental behavior, most studies suggest that attitudes do have some impact; therefore, it is important to explore and understand the mechanisms by which attitudes may be

${ }^{\dagger \dagger}$ The image is available at: https://www.adsoftheworld.com/media/print/winter [28.04.2020] 
changed, particularly when pursuing behavioral change (Heimlich, Ardoin 2008: 221). Correspondingly, we claim that developing a positive relationship with things may result in an impulse to take better care of them. To confirm it, obviously, an empirical study would be required. A well-designed study could offer us valuable insights into which motivations related to artifacts in fact do work (or work better), or under what conditions they are more effective, applicable, etc. The good material for such a study could be obtained by comparing change in attitudes in behaviors of students in response to classes employing various kinds of motivation for environment protection. In the next section, we offer three possible class scenarios following the path of positive intrinsic motivation to take better care of artifacts.

\section{Practical implications - classroom activities}

Numerous studies have indicated that properly structured classrooms promote student motivation (Skinner et al. al. 2012). Csíkszentmihályi (2014: 176) argues that "teaching involves changing the learners' cognitive structures, and, more important, changing their goal structures." The "intrinsic motivation is considered the desired type of motivation in students" (Kusurkar et al. 2011: 978), because there is a link between intrinsic motivation and productivity, or "deep, spontaneous involvement with the task at hand" (Csíkszentmihályi 2014: 181). A well-structured class needs to make a student feel "so immersed in the activity that the distinction between "I" and "it" becomes irrelevant." (Csíkszentmihályi 2014: 181)

Autonomy-supportive instruction (giving choices, making learning relevant) has also been linked to engagement (Skinner et al. al. 2012; Reeve, Jang, Carrell, Jeon, \& Barch, 2004). The underlying framework for this is Self-Determination Theory (SDT), upon which the typology of motivations (amotivation, extrinsic motivation, intrinsic motivation) is also built (Ryan and Deci 2020; Skinner et al. 2012; Darner 2012; 2009). 345678

The SDT model rests on three pillars: relatedness (feeling welcome and a sense of belonging); competence (feeling efficacious) and autonomy (feeling self-determined). Skinner et al (2012) show that the need for relatedness can be met by cooperation with and acceptance from classmates, teachers, and other significant actors; the need for competence may be met by experiences of how problem-solving, effort, and persistence pay off in tangible outcomes, and the sense of autonomy can be supported by activities that develop pride and ownership.

We believe that environmental educators can utilize the SDT model to instill positive motivation to be mindful not only about elements of the natural environment, but also artifacts, developing respect, appreciation, and the sense of responsibility for them. The practical implications of this model require teacher or mentors to identify and nurture what students need and want, encourage active participation (Kusurkar et al. 2011: 979). However, the autotelic nature of true learning must always be highlighted - "it is important for teachers and parents not to emphasize too much the instrumental aspects of education" (Csíkszentmihályi 2014: 184).

In what follows, we offer three possible topics that they may cover in this regard. We focus on classes for early tertiary education, which obviously varies greatly across the world, but basically includes students between ages 16-19 (Katona et al. 2008).

\section{Class 1. What is the Environment?}

The first topic aims to unpack the extent to which artifacts constitute our everyday environment. Unlike in urban environmental education, which is an extremely interesting field, classrooms adapting a positive orientation toward artifacts would be focused not on searching wildlife or nature in our immediate surroundings, but in rediscovering artifacts as inherent parts of it (Kirkman 2010). 
A good starting point can be to read selected passages from Steven Vogel's Thinking like a Mall (2015). It tells the story of a mall in Ohio from the moment it was built to its demolition and argues that we should reconsider our indifference to it. Vogel reminds us that not only buildings, but also single artifacts, such as toasters, "environ" us. We recommend assignments that allow the students to reconstruct their environment with an awareness of being 'environed': e.g. have them build a list of things in their surroundings with which they engage on a daily basis. The familiar examples can make students "feel autonomous and competent in their learning" (Kusurkar et al. 2011: 979).

This kind of activity draws upon the idea of ecological education through engagement with nature; it cultivates a sense of connectedness with nature that results in thoughts about ecological ethics (Yi 2019). We propose to modify it by referring not only to nature but to all the things in students' surroundings. This may help students better experienced the "state of being environed, that is, surrounded, encircled, encompassed," (Yi 2019) which is what environment effectively is. Furthermore, it refers to the theory of place dependence (Moore and Graefe 1994), which says the extent to which a particular setting serves a person's needs for a desired activity results in an affective bond between that person and that specific place (Vaske and Kobrin 2001). Realizing what a significant part of the everyday environment consists of artifacts can contribute to establishing a similar bond between students and artificial objects. Such an examination shall not praise the dominance over nature, but give rise to critically rethink is it ethically appropriate to be indifferent to artifacts, treat them merely as a necessary evil, or at best be extrinsically concerned with them in order to limit negative ecological impact.

This task targeted at revisiting the attitude to artifacts can include the discussion on what it means to engage with artifacts in order to build a sense of being in relation with things; how is this different than and similar to being in relation with animate beings? Another step might be to rename those items creatively in a way that expresses their/our dependence upon them, e.g. a toaster oven might become a 'lunch warmer' or a 'cheese melter'. This may result in a deeper appreciation of their helpful character that is so often taken for granted, .

\section{Class 2. What our things mean to us}

The second topic is concerned with the meaning we attach to our things, not necessarily regarded as "personal" (for instance, a bed, keys, backpack). Attaching meaning to artifacts tends to illuminate their uniqueness, thereby increasing our appreciation, which can in turn give rise to a concern for environmental issues.

The classroom scenarios employing such a strategy vis-à-vis artifacts can request narratives from the students about the things they use on a daily basis. Students choose and bring one of the objects (or the picture of it), and describe the thing as well as their patterns of using it. According to the SDT, giving choices to the students whenever possible is a way to develop their autonomy (Kusurkar et al. 2011: 981).

A teacher or instructor can direct the narrative towards the issues of responsibility, dependence and the possible attachment to this particular thing, cultivating a sense for Leopold's 'great possessions'. The questions can be variations on the following: how often do you use this particular thing? Since when do you possess it? What can you do to maintain it in a good condition? Can we repair it? Can you think of any other object which is similarly helpful for you? etc. Such a discussion can encourage students to cherish their stuff and rethink the problem of consumption and replacing things, which may contribute to limiting waste.

\section{Class 3. Practical upcycling}


The third topic is related to recycling and upcycling. The distinctive character of this suggested pedagogical approach is that it will advocate recycling and upcycling for the sake of things themselves and not only for nature. That is to say, recycling and upcycling is not only about diminishing waste but about fulfilling the material potential of the artifact, which is a concrete individual.

An effective idea is to encourage students to do recycling or upcycling in the class. This would entail converting waste materials into objects that can be reused for the original purpose or other goals, or in the case of upcycling, restoring things to their functionality or giving them a new form. This type of task is in line with the SDT model, which suggests performing activities oriented toward developing a sense of competence and autonomy. It also builds upon the Remida approach ${ }^{\ddagger \neq}$, which introduces artwork utilizing reusable materials as part of the pedagogical practice (Jørgensen, Madsen, Læssøe, 2017).

The teacher can focus on explaining better the differences between recycling and upcycling, and encourage students to take up a project in real life and document the process in order to then present it to the class. The important thing is, however, that "students should not be forced to take part in these activities, but participate out of their own volition" (Kusurkar et al. 2011: 980), if their intrinsic motivation is to be increased rather than lost.

This activity also presents a good opportunity to discuss global and social inequalities in the context of environmental protection. For instance, teachers can point out that for some people things are defined as 'worn out' much later than for those from more wealthy and privileged regions of the world, which is related to the standard of living and availability of things.

Extrinsic (economical) motivation to recycle und upcycle does not seem to be a strong enough incentive for students who are members of developed societies where consumer goods are easily accessible, come from wealthy families, or are not concerned with financial issues for any other reason. Of course, such students can be motivated by a willingness not to harm nature by overconsumption resulting in massive amount of waste (intrinsic negative motivation) and due to that recycle and upcycle, but the intrinsic grounding for it (fulfilling the potential of the particular thing) can further strengthen their efforts to do so. Such a possibility makes it, in our view, worth pursuing this idea.

\section{Conclusions}

In this paper, we sketched an alternative for teaching the environmental ethics of artifacts and offer some suggestions for class activities based on it. The main argument of the paper is that environmental education can and should implement a new strategy in teaching up-and-coming generations how to deal with artifacts in an ecological manner. The reversal in question consists of developing a fully intrinsic and positive motivation to take care of them, which entails cultivating the sense of attachment and responsibility for things along with an appreciation of their unique and useful character. This uniqueness is understood as being a single individual that, as such, does not have any duplicates - it is always a separate object, which we can buy instead of the previous one. Such a perspective can make us more mindful and respectful about the artifacts we deal with on a daily basis. Furthermore, our appreciation of things can be further deepened by gratitude for how they facilitate our everyday life, rather than seeing them as a necessary evil (from an ecological point of view). Balancing between the two latter perspectives seems to be essential in developing an environmental ethics of artifacts. ¥¥ Remida is named after the myth of King Midas, about whom it is said that everything he touched
turned to gold (Jørgensen, Madsen, Læssøe, 2017). 
Correspondingly, we do not seek to eliminate or replace motivation oriented directly toward nature (which is usually identified with intrinsic motivation) by offering positive motivation to take care for artifacts. In our view, they do not compete, but rather can mutually strengthen or complement each other. The message of the importance of reducing activities which are harmful to nature may not reach everyone, as it may appear insufficiently definite and concrete or may excessively call upon negative emotions (guilt, dreariness). Instead, we propose a complimentary justification for pro-environmental behavior that would be anchored in a positive attitude toward artifacts as an indispensable part of our environment which help us on a daily basis. This can be more compelling for those who are discouraged by negative strategy, or be an additional support for it.

Such a reorientation can have implications for environmental education. Classrooms designed for secondary and tertiary education that adopt this alternative perspective will tell a different narrative of things, thereby shifting human patterns of dealings with things, which will in turn hopefully bring about a pro-environmental change.

\section{References}

Aguirre-Bielschowsky, Ikerne Claire Freeman \& Eva Vass (2012) Influences on children's environmental cognition: a comparative analysis of New Zealand and Mexico, Environmental Education Research, 18:1, 91-115.

Annila, A., \& Kolehmainen, E. (2015). On the divide between animate and inanimate. Journal of Systems Chemistry, 6(1), 2. https://doi.org/10.1186/s13322-015-00088. Accessed 01 Mar 2019

Aristotle (1999), Metaphysics, trans. W.D. Ross, Digireads.com.

Braun Tina, Richard Cottrell \& Paul Dierkes (2017): Fostering changes in attitude, knowledge and behavior: demographic variation in environmental education effects, Environmental Education Research ; Volume 24, 2018 - Issue 6, 899920

Brennan, A. (1988). Thinking about nature. An investigation of nature, value and ecology. Athens: The University of Georgia Press.

Brennan, Andrew (1984) "The Moral Standing of Natural Objects," Environmental Ethics 6:1: $35-56$

Breunig Mary, Jocelyn Murtell, Constance Russell \& Ryan Howard (2014) The impact of integrated environmental studies programs: are students motivated to act proenvironmentally?, Environmental Education Research, 20:3, 372-386

Callicott, J. B. (1980). Animal liberation: A triangular affair. Environmental Ethics, 2, 31132.

Carlson Rachel. (2002), Silent Spring. Houghton Mifflin Company.

Cooke Anna N., Kelly S. Fielding \& Winnifred R. Louis (2016) Environmentally active people: the role of autonomy, relatedness, competence and self-determined motivation, Environmental Education Research, 22:5, 631-657.

Corral Verdugo Victor. (2012). The positive psychology of sustainability, Environment, Development, Sustainability, 14:651-666.

Csíkszentmihályi M. (2014) Intrinsic Motivation and Effective Teaching. In: M. Csíkszentmihályi, Applications of Flow in Human Development and Education. Springer, Dordrecht, pp. 173-187. 
Darner Rebekka (2012) An empirical test of self-determination theory as a guide to fostering environmental motivation, Environmental Education Research, 18:4, 463-472.

Darner Rebekka. (2009). Self-Determination Theory as a Guide to Fostering Environmental Motivation, The Journal of Environmental Education, 40:2, 39-49.

Donovan, Rob; Henley Nadine. (2010). Principles and Practice of Social Marketing: An International Perspective. Cambridge: Cambridge University Press.

Duhn, Iris; Karen Malone, Marek Tesar. (2017). Troubling the intersections of urban/nature/childhood in environmental education, Environmental Education Research, 23:10, 1357-1368.

Dutta Deborah \& Sanjay Chandrasekharan (2018) Doing to being: farming actions in a community coalesce into pro-environment motivations and values, Environmental Education Research, 24:8, 1192-1210

EPA (2020). What is Environmental Education? https://www.epa.gov/education/whatenvironmental-education.

Ernst, J., \& Theimer, S.. (2011). Evaluating the effects of environmental education programming on connectedness to nature. Environmental Education Research, 17(5), $577-598$.

Gerber Lisa, (2002). What is So Bad about Misanthropy?, Environmental Ethics 24(1): 41-55.

Gerber Lisa, (2018). Aldo Leopold's “Great Possessions", Environmental Ethics, 30: 3: 269-282.

Gola Beata, (2017), Is formal environmental education friendly to nature? Environmental ethics in science textbooks for primary school pupils in Poland, Ethics and Education, 12:3, 320-336.

Goodpaster Kenneth.(1978), "On Being Morally Considerable," Journal of Philosophy 75(6): 308-325.

Gosling E.; Williams K. J.H, (2010): Connectedness to nature, place attachment, and conservation behaviour: Testing connectedness theory among farmers, Journal of Environmental Psychology, 30:3: 298-304.

Grasso Marco, Katia Vladimirova. (2020). A Moral Analysis of Carbon Majors' Role in Climate Change, Environmental Values 29:2 175-195.

Hadjichambis, Andreas, Pedro Reis (2019) Introduction to the Conceptualisation of Environmental Citizenship for Twenty-First-Century Education. In Andreas Hadjichambis Pedro Reis Demetra Paraskeva-HadjichambiJan ČinčeraJelle Boeve-de PauwNiklas GerickeMarie-Christine Knippels (eds), Conceptualizing Environmental Citizenship for 21st Century Education. Springer: Dodrecht.

Hailwood, Simon. 2015. Alienation and Nature in Environmental Philosophy. Cambridge: Cambridge University Press.

Hartig, T., Kaiser, (2001) Psychological restoration in nature as a positive motivation for ecological behavior, Environment and Behavior, 33:4, 590-607.

Heimlich Joe E., Nicole M. Ardoin (2008) Understanding behavior to understand behavior change: a literature review, Environmental Education Research, 14:3,

215-237.

Hoły-Łuczaj, M., Artifacts and the limitations of moral considerability, Environmental Ethics, 2019, 41(1), pp. 69-87

Hoły-Łuczaj, M., Postnatural-Environmental Ethics of Artifacts as a Challenge to Capitalism, Capitalism, Nature, Socialism, 2020.

Hoły-Łuczaj, M., Blok, V., Hybrids and the Boundaries of Moral Considerability or Revisiting the Idea of Non-Instrumental Value, Philosophy and Technology, 2019. https://doi.org/10.1007/s13347-019-00380-9

Houkes W., Vermaas P.E., (2004) Actions versus Functions: A Plea For an Alternative Metaphysics of Artifacts, Monist 87:1: 52-71. 
Houkes, W., \& Vermaas, P. E. (2009). Produced to use: combining two key intuitions on the nature of artefacts. Techne: Research in Philosophy and Technology, 13(2), 123-136.

Howell Rachel A. \& Simon Allen (2019) Significant life experiences, motivations and values of climate change educators, Environmental Education Research, 25:6, 813-831.

Jakovcevic A., Steg, L. Mazzeo N., Caballero R., Franco P., Putrino N., Favara J., (2014), Charges for plastic bags: Motivational and behavioral effects, Journal of Environmental Psychology 40: 372-380.

Joanes, Wencke, Gwozdz, Christian A. Klöckner. (2020) Reducing Personal Clothing Consumption: A Cross-cultural Validation of the Comprehensive Action Determination Mode, Journal of Environmental Psychology, in press.

Jonas H. Rees \& Sabine Klug \& Sebastian Bamberg (2014), 'Guilty conscience: motivating pro-environmental behavior by inducing negative moral emotions,' Climatic Change 130: 439-452.

Jones, N. (2018) How to stop data centres from gobbling up the world's electricity, Nature $561,163-166$.

Jørgensen, N. J., Madsen, K. D., \& Læssøe, J. (2017). Waste in education: the potential of materiality and practice. Environmental Education Research, 24(6), 807-817.

Junot, A, Paquet, Y, Fenouillet, F. (2018) Place attachment influence on human wellbeing and general pro-environmental behaviors. J Theo Soc Psychol. 2: 49- 57.

Kaiser, F., Schultz, P. W., Berenguer, J., Corral-Verdugo, V., \& Tankha, G. (2008). Extending planned environmentalism. Anticipated guilt and embarrassment across cultures. European Psychologist, 13, 288-297.

Kaplan, S. (2000). Human nature and environmentally responsible behavior. Journal of Social Issues, 56, 491-508.

Mintz Keren \& Tali Tal (2018) The place of content and pedagogy in shaping sustainability learning outcomes in higher education, Environmental Education Research, 24:2, 207-229.

Morrison, Scott A. (2018) Everyday environmental education: five practices of ecologically minded teachers, Environmental Education Research, 24:11, 15271545.

Kirkman Robert, (2010), The Ethics of Metropolitan Growth. The future of Built Environmnet. Continnum London.

Kollmuss Anja \& Julian Agyeman (2002) Mind the Gap: Why do people act environmentally and what are the barriers to pro-environmental behavior?, Environmental Education Research, 8:3, 239-260.

Kroes P., Vermaas P.E., 2008, Interesting Differences between Artifacts and Natural Objects, „APA Newsletter”, vol. 8, no. 1.

Kronlid, David (2003). Ecofemisnim and Environmental Ethics. An Analysis of Ecofemnist Ethical Theory. Uppsala: Uppsala University Press.

Kusurkar R., Croiset G., Ten Cate T. (2011) Twelve tips to stimulate intrinsic motivation in students through autonomy-supportive classroom teaching derived from selfdetermination theory. Medical Teacher 33: 978-982.

Lee, K. (1999). The Natural and the Artefactual. The implications of deep science and deep technology for environmental philosophy. Lanham: Lexington Books.

Leopold, A. (1987). The land ethic. In A. Leopold (Ed.), A sand county almanac: and sketches here and there. Oxford: Oxford UP

Light Andrew, Holmes Rolston III, "Introduction: Ethics and Environmental Ethics." In: Environmental Ethics. An Anthology, A. Light, Holmes Rolston III (eds.) (Blackwell Publishing, Malden (MA) 2012).

Lindenberg, S., \& Steg, L. (2007). Normative, gain and hedonic goal frames guiding environmental behavior. Journal of Social Issues, 63, 117-137. 
Malott, R. W. (2010). I'll save the world from global warming-tomorrow: Using procrastination management to combat global warming. The Behavior Analyst, 33, 179-180.

McShane, Kathrine. 2007. Why Environmental Ethics Shouldn't Give Up on Intrinsic Value. Environmental Ethics 29:1: 43-61.

Moreira Jorge, Fátima Alves, and Ana Mendonça, (2020), Questioning Nature and Environmental Ethics in Schools. In: Oxford Research Encyclopedias. doi: 10.1093/acrefore/9780190264093.013.687

Murray, H. W. (1980). Are mere things morally considerable? Environmental Ethics, 2(3), $59-65$.

Naess Arne 1995, The Shallow and the Deep Lng-Range Ecology Movement: A Summary. In: The Deep Ecology Movement. An Introductory Anthology, Alan Drengson, Yuichi Inoue (eds.) Berkeley: North Atlantic Books 1995.

Naess, A., \& Sessions, G. (1995). Platofrm principles of the deep ecology movement. In: The Deep Ecology Movement. An Introductory Anthology, Alan Drengson, Yuichi Inoue (eds.) Berkeley: North Atlantic Books 1995.

O'Neill, J. (2012). The varieties of intrinsic value. In A. Light \& H. Rolston III (Eds.), Environmental Ethics. An Anthology. Malden: Blackwell Publishing

Parra Gema, Ralph Hansmann, Andreas Ch. Hadjichambis, Daphne Goldman, Demetra Paraskeva-Hadjichambi, Per Sund, Louise Sund, Niklas Gericke, and Daniela Conti (2019) Education for Environmental Citizenship and Education for Sustainability In Andreas Hadjichambis Pedro Reis Demetra ParaskevaHadjichambiJan ČinčeraJelle Boeve-de PauwNiklas GerickeMarie-Christine Knippels (eds), Conceptualizing Environmental Citizenship for 21st Century Education. Springer: Dodrecht.

Regan, T. (1983). The case for animal rights. Berkeley: University of California Press.

Ryan, Richard, M. Edward L. Deci (2020) Intrinsic and extrinsic motivation from a selfdetermination theory perspective: Definitions, theory, practices, and future directions. Contemporary Educational Psychology, in press.

Seetharam, Anand Manikandan Somasundaram, Don Towsley, Jim Kurose, and Prashant Shenoy. 2010. Shipping to streaming: is this shift green? In Proceedings of the first ACM SIGCOMM workshop on Green networking (Green Networking '10). Association for Computing Machinery, New York, NY, USA, 6168. DOI:https://doi.org/10.1145/1851290.1851304

Shang, Rong-An, Yu-Chen Chen, Lysander Shen (2005) Extrinsic versus intrinsic motivations for consumers to shop on-line, Information \& Management 42: 401413.

Siipi, H. (2003). Artefacts and living artefacts. Environmental Values, 12(4), 413-430.

Simmons Deborah \& Ron Widmar, (1990) Motivations and Barriers to Recycling: Toward a Strategy for Public Education. The Journal of Environmental Education, 22: 1318.

Singer, P. (1975). Animal liberation: a new ethics for our treatment of animals. New York: Avon.

Singer, P. (1989). All animals are equal. In: T. Regan and Peter Singer (eds.), Animal Rights and Human Obligations. New Jersey: Prentice-Hall, 1989, 148-162.

Skinner Ellen A., Una Chi a \& The Learning-Gardens Educational Assessment Group, (2011), Intrinsic Motivation and Engagement as "Active Ingredients" in GardenBased Education: Examining Models and Measures Derived From SelfDetermination Theory, The Journal of Environmental Education, 43:1, 16-36.

Taylor, P. (1986). Respect for nature. Princeton UP: Princeton.

Thompson, Derek. (2014). Why America's Essentials Are Getting More Expensive While Its Toys Are Getting Cheap, retrieved: 
https://www.theatlantic.com/business/archive/2014/05/its-expensive-to-bepoor/361533/

Vaccari Andres, Artifact Dualism, Materiality, and the Hard Problem of Ontology: Some Critical Remarks on the Dual Nature of Technical Artifacts Program, Philosophy \& Technology 26(1) (2011).

Vogel, S. (2003). The nature of artifacts. Environmental Ethics, 25(2), 149-168.

Vogel, S. (2015). Thinking like a mall. Cambridge: MIT Press.

Weston, A. (1996). Beyond intrinsic value: Pragmatism in environmental ethics. In E. Katz (Ed.), Environmental Pragmatism, (pp. 285-306). London.

Wokje Abrahamse., (2019), Encouraging Pro-Environmental Behaviour: What Works, What Doesn't, and Why. Academic Press, London.

Yi, Xiaoming (2019). Ecological education through aesthetic engagement, The Journal of Environmental Education, 50:3: 183-191. 
International Electronic Journal of Environmental Education

Vol.11, Issue 2, 2021, 111-126

RESEARCH ARTICLE 